\title{
IMPACT OF ENERGY POLICY INSTRUMENTS ON THE ESTIMATED \\ LEVEL OF UNDERLYING ENERGY EFFICIENCY IN THE EU \\ RESIDENTIAL SECTOR
}

\begin{abstract}
Massimo FILIPPINI
Centre for Energy Policy and Economics (CEPE), ETH Zurich, Zürichbergstrasse 18, CH-8032, Zürich, Switzerland, and Department of Economics, University of Lugano, Tel: +41 44632 0649, Fax: +41 4463216 22, massimo.filippini@usi.ch
\end{abstract}

\section{Lester C. HUNT}

Surrey Energy Economics Centre (SEEC), School of Economics, University of Surrey, Guildford, GU2 7XH, UK, Tel: +44(0)1483 686956, Fax: + 44(0)1483 689548, E-mail: L.Hunt@ surrey.ac.uk

\author{
Jelena ZORIĆ \\ Faculty of Economics, University of Ljubljana, Kardeljeva pl. 17, 1000 Ljubljana, \\ Slovenia, Tel: +386 15892 785, Fax: +386 15892 698, E-mail: \\ jelena.zoric@ef.uni-lj.si (corresponding author)
}

\begin{abstract}
The promotion of energy efficiency is seen as one of the top priorities of EU energy policy (EC, 2010). In order to design and implement effective energy policy instruments, it is necessary to have information on energy demand price and income elasticities in addition to sound indicators of energy efficiency. This research
\end{abstract}


combines the approaches taken in energy demand modelling and frontier analysis in order to econometrically estimate the level of energy efficiency for the residential sector in the EU-27 member states for the period 1996 to 2009. The estimates for the energy efficiency confirm that the EU residential sector indeed holds a relatively high potential for energy savings from reduced inefficiency. Therefore, despite the common objective to decrease 'wasteful' energy consumption, considerable variation in energy efficiency between the EU member states is established. Furthermore, an attempt is made to evaluate the impact of energy-efficiency measures undertaken in the EU residential sector by introducing an additional set of variables into the model and the results suggest that financial incentives and energy performance standards play an important role in promoting energy efficiency improvements, whereas informative measures do not have a significant impact.

Key words: energy efficiency, residential energy demand, stochastic frontier analysis

\section{Introduction}

In 2010, the EU adopted a new energy strategy Energy 2020 - a strategy for competitive, sustainable and secure energy, where the increase in the level of energy efficiency is listed among five priorities (EC, 2010). Improving energy efficiency is viewed to be one of the most cost-effective ways of reducing greenhouse gas emissions, increasing security of energy supply, leading to more sustainable energy policy and enhancing industry competitiveness. Member states are, in comparison with projected trends, expected to achieve $20 \%$ savings of its primary energy 
consumption by 2020. However, the latest report by the European Commission (EC, 2011a) suggests that with the present policies the EU will achieve only half of the 20 $\%$ target in 2020. This is claimed not to be because of the lack of economic potential but because of market failures, regulatory failures and also the rebound effect. In order to close this gap, a new directive on energy efficiency was adopted in 2012 (Directive 2012/27/EU).

Defining and measuring energy efficiency is yet another challenge. Energy efficiency is typically approximated by energy intensity, despite several shortcomings related to this measure. For example, EC (2000, p. 3) recognises that "Changes in energy intensity for final energy consumption are a first and rough estimate indicator for changes in energy efficiency. This is due to the fact that energy intensity can also include temperature effects and the weighting effects of economic restructuring." In the same manner IEA (2009, p. 19) notes that "Energy intensity is the amount of energy used per unit of activity. It is commonly calculated as the ratio of energy use to GDP. Energy intensity is often taken as a proxy for energy efficiency, although this is not entirely accurate since changes in energy intensity are a function of several factors including the structure of the economy and energy efficiency."

Therefore, following an approach based on microeconomic production theory proposed by Filippini and Hunt $(2011,2012)$ and Evans et al. (2013), this paper uses an econometric approach to estimate the level of energy efficiency for each member state. Based on this measure it is then possible to identify the saving potential that can be reached with improvement in the level of energy efficiency. In this context, 
the EU member states may decide to improve or introduce new energy policy instruments. From the policy makers' point of view it is important to have information on the effectiveness of energy policy instruments designed to increase the level of energy efficiency. For instance, one of the interesting questions is to know if performance standards are more effective than monetary incentives. In fact, during the last two decades most of the EU member states have introduced performance standards in buildings, heating systems and electrical appliances in an attempt to improve the level of energy efficiency in the residential sector, whereas others have also introduced monetary incentives such as subsidies and tax credits. From the research point of view it is therefore interesting to analyse the impact of different policy instruments on the level of energy efficiency. In order to do so, two issues should be addressed. First, how to define and measure the level of energy efficiency and, second, how to empirically identify the impact of introduced policy measures.

As stated above, this paper uses the approach introduced by Filippini and Hunt $(2011,2012)$ to define and measure energy efficiency based on the theory of productive efficiency. ${ }^{1}$ Therefore, a stochastic frontier framework for the empirical analysis of energy efficiency is used, as opposed to the more conventional indicator of energy intensity. This econometric measure of energy efficiency controls for a range of economic and other factors and is therefore viewed as a more suitable approach to measure energy efficiency. ${ }^{2}$ Therefore, a stochastic frontier analysis (SFA) is employed to estimate a 'frontier' residential energy demand function using unbalanced panel data for EU member states over the period 1996 to 2009. Additionally, a set of policy variables is considered in the model to evaluate the 
impact of energy efficient measures on promoting energy efficiency in the EU member states.

Literature that attempts to analyse the impact of energy efficiency measures on the level of energy efficiency is relatively scarce. Bigano et al. (2011) investigate the influence of adopted energy efficiency policies and measures on energy intensity, energy security and carbon intensity index using an econometric approach; but not based on the estimation of a frontier function. Instead, Bigano et al. (2011) use energy intensity as a proxy for energy efficiency and regress it on several factors such as price, income and dummy variables representing the presence of energy policy measures promoting the level of energy efficiency. Further, following Filippini and Hunt (2011, 2012), Saussay et al. (2012) make use of the SFA approach to analyse the impact of introduced building codes on the energy efficiency of residential space heating in selected European countries. However, the correction for unobserved heterogeneity in estimating energy efficiency is not considered in their model. Hence, the analysis undertaken here builds on previous works and explicitly takes into account unobserved heterogeneity and furthermore considers a broad set of energy efficiency measures to estimate the effect of implemented energy efficiency measures on energy efficiency of the EU residential energy demand.

The rest of the paper is organised as follows. Section 2 provides an overview of the EU energy policy objectives and measures implemented in the area of energy efficiency. Section 3 elaborates on the methodology and specification of the energy demand frontier function, which is followed by Section 4 where the data employed 
to estimate the model are presented. Section 5 provides the estimation results and discusses the main findings, while Section 6 sets out relevant policy implications and concludes the paper.

\section{Energy-efficiency policy measures in the EU}

Promotion of the efficient use of energy ${ }^{3}$ has received a lot of attention and has been an important policy objective of the EU member states ever since the oil shocks in the 1970s, where in the context of high oil prices energy savings became important for reducing energy import dependence. As a result of implemented policy measures and structural changes of the economies, member states have been able to decouple economic growth from energy consumption (IEA, 2009). Nevertheless, as reported in EC (1998) and IEA (2007), the rate of decline in energy intensity in the EU-15 and G8 countries was found to be higher before the 1990s than afterwards. Hence, despite the EU commitment to promote energy savings and various initiatives, programmes and instruments introduced at the Community level, the results turned out to be dissatisfactory. According to EC (2000) this could be attributed to decreasing energy prices and relatively low priorities given to energy saving measures and demand-side management by member states. Also, several market failures and barriers to investments in energy-efficiency have been identified by EC (2000) such as the lack of information, technical, institutional, legal, and financial barriers.

The action in the field of energy efficiency policy was revived as a response to rising energy security issues and commitment to achieve environmental targets set up by 
the Kyoto protocol. Council of the EU (1998) set a target to improve energy intensity of final consumption by a further one percentage point per year, on average, over that which would have otherwise been attained in order for the EU to realise its full potential for energy savings by 2010. Policies and measures for removal of the market barriers and realisation of the energy saving potential were further laid down in Action Plan to Improve Energy Efficiency in the European Community (EC, 2000). In line with the findings reported in the Green Paper on Energy Efficiency or Doing More with Less (EC, 2005) these efforts again proved to be insufficient and in the light of increasing energy prices and environmental concerns a new round of energy efficiency debates was launched. The Green Paper estimated that the EU holds a potential to achieve a reduction of energy consumption by $20 \%$ compared to the projections for 2020 in a cost-effective way. The Action Plan for Energy Efficiency: Realising the Potential that followed proposed a range of cost-effective measures to realise the $20 \%$ saving potential (EC, 2006).

In 2006, Directive 2006/32/EC on energy end-use efficiency and energy services was adopted according to which the EU member states are to achieve a 9\% saving in final energy consumption in the period from 2008 to 2016. In line with this, member states were required to prepare National Energy Efficiency Action Plans (NEEAPs) laying down various sector-specific, cross-sectoral and horizontal measures which would allow achieving indicated savings in the nine-year period. It is worth noting that the target set by the directive is not mandatory but only indicative. Also, it is claimed not to aim at realizing the full estimated potential for energy savings, but is rather seen as an important first step towards reaching the $20 \%$ target. Therefore, the recently issued Energy Efficiency Plan 2011 envisages new measures that are 
expected to close this gap (EC, 2011b). It was furthermore accompanied by a proposal of new energy-efficiency directive (Directive 2012/27/EU) which became effective in 2012.

According to EC (2006) the residential sector is estimated to represents roughly 17 $\%$ of total primary energy consumption and $25 \%$ of the final energy consumption in the EU. It has been identified to have the most potential for cost-effective savings which are estimated to be $27 \%$, where huge energy saving opportunities lie in retrofitted roof and wall insulation of buildings as well as improved appliances and other energy-using equipment. Despite this, arguably the progress in achieving energy savings so far has been relatively slow. While according to ADEME (2009) improvement in the EU's final energy consumption between 1996 and 2007 was found to be $13 \%$, the residential sector improved only by $8 \%$ on average. Considerable variation in achieved progress between countries can also be established where more than half of the member states realised less than the $1 \%$ annually requested in the Energy Efficiency and Energy Service Directive (2006/32/EC).

Despite the huge potential for cost-effective energy-saving measures in the residential sector established by several EU official documents, it is found that their implementation is hindered by various hurdles such as a lack of investment funds, information gap, transaction cost, adverse incentives for owners and tenants and other institutional barriers. Therefore, several energy policy instruments have been introduced by the EU member states to promote energy efficiency. An overview of adopted measures in Table 1 reveals the predominant use of legislative measures 
(i.e., energy performance standards) and financial incentives (e.g., subsidies and tax deductions), while informative measures such as labelling and informational and educational campaigns seem to be used to a somewhat lower extent. The number of implemented energy-efficiency measures and policy mix are, of course, found to vary by member states.

While performance standards (e.g., relating to insulation standards of new and existing buildings, efficiency of boilers, heating systems and electrical appliances) generally have a long lifetime and get stricter over time, this may not hold for financial incentives and informative campaigns, especially since they are not necessarily provided on a continuous basis (ADEME, 2009). Nevertheless, the impact of individual measures should not be evaluated in isolation, since several different measures are usually required for an effective policy mix. A package of financial incentives typically supports various programmes related to energyefficient renovation of buildings and sustainable building construction, installation of energy-efficient heating systems, efficient electricity use and schemes for efficient energy use for low-income households. To facilitate behavioural changes this is furthermore accompanied by educational and awareness-raising campaigns, provision of information, promotional and training programmes and demonstration projects. According to ADEME (2009) many implemented energy efficiency measures in the member states are the result of the EU policy, such as the directives on energy efficiency and energy services, energy performance of buildings, labelling of electrical appliances and eco-design for energy using products. In the residential sector EU energy efficiency policies seem to have particularly strong impact as they already represent about one third of all implemented measures at the national level. 


\begin{tabular}{|c|c|c|c|c|c|c|c|}
\hline \multirow[b]{2}{*}{ Member state } & \multirow[b]{2}{*}{ MS } & \multicolumn{5}{|c|}{ Number of policy measures by measure type } & \multirow[b]{2}{*}{ Total } \\
\hline & & $\begin{array}{c}\text { Legislative/ } \\
\text { Performance } \\
\text { standards }\end{array}$ & $\begin{array}{l}\text { Legislative/ } \\
\text { Informative } \\
\text { - Labelling }\end{array}$ & $\begin{array}{c}\text { Information/ } \\
\text { Education }\end{array}$ & $\begin{array}{c}\text { Financial/ } \\
\text { Fiscal }\end{array}$ & Other & \\
\hline Austria & $\mathrm{AT}$ & 7 & 2 & 6 & 7 & 1 & 23 \\
\hline$\underline{\text { Belgium }}$ & $\mathrm{BE}$ & 9 & 6 & 6 & 16 & 0 & 37 \\
\hline$\underline{\text { Bulgaria }}$ & $\mathrm{BG}$ & 13 & 6 & 0 & 8 & 0 & 27 \\
\hline Cyprus & $\mathrm{CY}$ & 6 & 3 & 1 & 1 & 0 & 11 \\
\hline Czech Republic & $\mathrm{CZ}$ & 10 & 3 & 4 & 7 & 0 & 24 \\
\hline Denmark & $\mathrm{DK}$ & 9 & 8 & 8 & 6 & 1 & 32 \\
\hline Estonia & $\mathrm{EE}$ & 8 & 5 & 5 & 10 & 0 & 28 \\
\hline Finland & FI & 8 & 6 & 10 & 7 & 1 & 32 \\
\hline France & FR & 15 & 8 & 5 & 24 & 1 & 53 \\
\hline Germany & $\mathrm{DE}$ & 18 & 12 & 4 & 7 & 4 & 45 \\
\hline Greece & GR & 11 & 6 & 3 & 13 & 2 & 35 \\
\hline Hungary & $\mathrm{HU}$ & 10 & 7 & 8 & 25 & 0 & 50 \\
\hline Ireland & $\mathrm{IE}$ & 13 & 2 & 6 & 8 & 0 & 29 \\
\hline Italy & IT & 17 & 10 & 2 & 5 & 0 & 34 \\
\hline Latvia & $\mathrm{LV}$ & 12 & 2 & 2 & 7 & 0 & 23 \\
\hline Lithuania & $\mathrm{LT}$ & 3 & 0 & 0 & 3 & 0 & 6 \\
\hline Luxembourg & $\mathrm{LU}$ & 12 & 0 & 3 & 17 & 0 & 32 \\
\hline Malta & MT & 2 & 1 & 4 & 6 & 0 & 13 \\
\hline Netherlands & NL & 4 & 2 & 4 & 8 & 8 & 26 \\
\hline Poland & $\mathrm{PL}$ & 4 & 2 & 0 & 4 & 0 & 10 \\
\hline Portugal & $\mathrm{PT}$ & 8 & 3 & 2 & 0 & 0 & 13 \\
\hline Romania & $\mathrm{RO}$ & 11 & 4 & 1 & 4 & 0 & 20 \\
\hline Slovakia & $\mathrm{SK}$ & 11 & 4 & 0 & 3 & 0 & 18 \\
\hline Slovenia & SI & 10 & 2 & 2 & 11 & 0 & 25 \\
\hline Spain & $\mathrm{ES}$ & 42 & 9 & 6 & 25 & 3 & 85 \\
\hline Sweden & SE & 4 & 7 & 4 & 6 & 2 & 23 \\
\hline $\begin{array}{l}\text { United } \\
\text { Kingdom } \\
\end{array}$ & UK & 25 & 3 & 10 & 15 & 2 & 55 \\
\hline Total & & 302 & 123 & 106 & 253 & 25 & 809 \\
\hline
\end{tabular}

Note: ${ }^{\text {a }}$ - The period refers to the start date of adopted policy measures. Only in the case of few reported measures the implementation is yet to take place during the following years.

Source: MURE II database (2012). 
As discussed later in the paper, the information included in Table 1 will be used to construct the variables considered in the econometric analysis that should reflect the choice and intensity of the energy policy instruments adopted in each EU member state.

\section{Methodology}

As previously mentioned, in this paper a stochastic frontier approach is used to estimate a residential frontier energy demand function. This allows for estimation of state specific levels of energy efficiency for the residential sector. Moreover, econometric specifications that give the possibility to analyse the impact of the energy policy instruments on the level of energy efficiency are utilised.

Within the framework of household production theory detailed in Deaton and Muellbauer (1980), residential demand for energy is a derived demand (i.e. derived from the demand for energy services such as a warm home, cooked food, hot water etc.). ${ }^{4}$ Households purchase energy together with other inputs such as labour and capital (in form of electrical appliances, heating system and insulation materials) to produce a composite energy service entering their utility function. Therefore, the production of energy services can be represented with a production function and a set of input demand functions. Nevertheless, because data on all inputs and input prices are generally not available, it is common in the energy economics literature to estimate only one input demand function, i.e. energy demand. Accordingly, in this paper the focus is on estimating an input demand function frontier which gives the 
minimum level of energy input used by a household for any given level of output. Also, it is worth noting that, as discussed in Schmidt and Lovell (1979) and in Kumbhakar and Lovell (2000), the difference between the observed input and the cost-minimizing input demand derived from a Cobb-Douglas production function, represents both technical as well as allocative inefficiency. Furthermore, the CobbDouglas production function implies that the level of technical and allocative efficiency is the same for all inputs. Moreover, in the context of production theory the term energy efficiency is imprecise. In fact, the level of productive efficiency is measured, i.e. an improvement of the productive efficiency determines a reduction of all inputs, not only a reduction of energy. ${ }^{5}$ However, in what follows the term energy efficiency will continue to be used in order to be in line with the energy economics literature.

Following the approach introduced by Filippini and Hunt (2011 and 2012) and based on the availability of the data, the following aggregate residential input energy demand function for EU-27 member states is specified:

$$
E D_{i t}=f\left(P E_{i t}, Y_{i t}, P O P_{i t}, D S I Z E_{i t}, H D D_{i t}, H O T_{i}, U E D T_{t}, E F_{i t}\right),
$$

where $E D_{i t}$ represents final residential energy consumption, $P E_{i t}$ the real energy price, $Y_{i t}$ real income, $P O P_{i t}$ population, $D S I Z E_{i t}$ the average size of a dwelling, $H D D_{i t}$ the number of heating degree days, $H O T_{i}$ a hot climate dummy variable, and $U E D T_{t}$ the underlying energy demand trend to capture the effect of technical progress (and other exogenous factors); all for a member state $i$ in year $t$. Furthermore, $E F_{i t}$ is introduced to capture the level of 'underlying energy efficiency' 
of the EU residential sector. A low level of 'underlying energy efficiency' implies an inefficient use of energy (i.e. 'waste energy'). This underlying energy efficiency indicator is not observed directly, but has to be estimated.

It is worth noting that, as discussed in Filippini and Hunt (2012), from the empirical point of view the impact of technological innovation and behavioural change on the energy consumption could be captured in different ways, which is either through the price effect, the income effect, the $U E D T_{t}$ or $E F_{i t}$ terms. Therefore, the measure of 'underlying energy efficiency' could also capture the waste of energy determined by the fact that a household is not using the most modern technology. In this context, we can identify two cases where households are producing an energy service without minimizing the use of inputs. In the first case, a household employing a modern technology is utilizing the inputs in an inefficient way, i.e. households are not minimizing the use of energy, labor and capital in the production of an energy service. In the second case, households are using a relatively old technology that does not allow the household to minimize the use of energy, labor and capital. In both cases, the level of energy used to produce a predefined level of energy services could be reduced, i.e. we have a situation characterized by "waste" energy. In general, this discussion suggests that a reduction of the energy consumption for the production of energy services could be determined by an improvement of the level of the productive efficiency and/or by the adoption of a modern energy-saving technology due to technical change.

One of the important issues in applying this approach is to measure the level of energy services produced within the residential sector. In fact, it is difficult to find 
indicators on these services such as the size of the heated rooms, lighting hours, number of cooked meals, hours of watching television etc. In order to solve this problem, at least partially, some variables are introduced in the model that indirectly reflect the level of energy services produced by the households such as dwelling size and the climate.

Following Filippini and Hunt (2011 and 2012) the stochastic frontier approach (SFA) is employed to estimate the 'frontier' energy demand function and 'underlying energy efficiency'. ${ }^{6}$ The frontier gives the minimum level of energy consumption necessary for households to produce any given level of energy services. If the residential sector of a member state is found to be on the frontier, it is considered to be energy efficient, while the deviation from the frontier is assumed to represent the inefficient use of energy. The level of energy inefficiency may differ over member states. These differences may occur as a result of various factors such as differences in capital equipment and technical appliances in use, differences in energy policy instruments and differences in behaviour as a reflection of different lifestyle, social norms and values.

The approach used in this study is based on the assumption usually considered in the stochastic frontier literature that the level of the energy inefficiency of the residential sector can be approximated by a one-sided non-negative term. Therefore, using a $\log$-log functional form and adopting the SFA approach, it is possible to specify the 'frontier' residential energy demand in Equation (1) in the following way: 


$$
\begin{aligned}
\ln E D_{i t}= & a_{(i)}+b_{P E} \ln P E_{i t}+b_{Y} \ln Y_{i t}+b_{P O P} \ln P O P_{i t}+b_{D S I Z E} \ln D S I Z E_{i}+ \\
& b_{H D D} \ln H D D_{i}+b_{H O T} H O T_{i t}+b_{t} t+v_{i t}+u_{i t},
\end{aligned}
$$

where the $U E D T_{t}$ is proxied by $t .^{7}$ The error term in (2) is assumed to be composed of two independent parts: a stochastic error $\left(v_{i t}\right)$, capturing the effect of noise, and a one-sided non-negative disturbance capturing the effect of inefficiency $\left(u_{i t} \geq 0\right)$. In line with Filippini and Hunt $(2011,2012)$ the second part, $u_{i t}$, is interpreted as an indicator of the inefficient use of energy.

In the literature on the estimation of a Stochastic Frontier Model (SFM) using panel data, it is possible to identify several models that could be used for the estimation of Equation (2). In this study, the focus is on the effects of energy policy measures on the level of energy efficiency. Therefore, the stochastic frontier models for panel data that allow the level of energy efficiency to vary over time and to depend on a set of covariates such as the presence of subsidies for energy efficient appliances or the presence of energy efficiency standards are selected. For this purpose, three suitable panel data models are identified: i) panel data model proposed by Battese and Coelli (1995) (BC95 hereafter); ii) the True Random Effects model (TRE hereafter); and iii) the True Fixed Effects model (TFE hereafter). ${ }^{8}$ These two last models have been proposed more recently by Greene (2005a and 2005b). All these approaches allow for the estimation of a stochastic frontier model in which the level of efficiency can be expressed as a specific function of explanatory variables. 
Following Battese and Coelli (1995) the inefficiency term $u_{i t}$ in Equation (2) is modified so as to have a systematic component associated with a vector of policy measures $\left(\mathbf{z}_{i t}\right)$ and a random component $\left(e_{i t}\right):^{9}$

$$
u_{i t}=\eta^{\prime} \mathbf{z}_{i t}+e_{i t}
$$

Energy-efficiency policy measures considered under $\mathbf{z}_{i t}$ consist of several groups of policy measures, namely performance standards of buildings and heating systems $\left(B H_{i t}\right)$, performance standards of electrical appliances $\left(A P P_{i t}\right)$, financial incentives $\left(F I N_{i t}\right)$ and informative measures $\left(I N F O_{i t}\right)$. This model can be estimated in a single stage by the maximum likelihood ML procedure where stochastic term is assumed to follow a normal distribution $v_{i t} \sim$ iid $N\left(0, \sigma_{v}^{2}\right)$ and inefficiency is assumed to follow a truncated normal distribution $u_{i t} \sim N^{+}\left(\eta^{\prime} \mathbf{z}_{i t}, \sigma_{u}^{2}\right)$.

Furthermore, the characteristic of the TRE and the TFE models is the inclusion of an individual random or fixed effect in the equation to be estimated. In these models individual effects should take into account all unobserved socioeconomic and environmental characteristics that are time-invariant. The TRE and the TFE models are therefore able to distinguish time invariant unobserved heterogeneity from the time varying level of efficiency component. The problem of these two models is that the level of inefficiency does not include the persistent inefficiencies that might remain more or less constant over time. To the extent that in the residential sector there are certain sources of energy efficiency that result in time-invariant excess energy consumption, the estimates of these models provide relatively high levels of energy efficiency. 
Further, the TRE and the BC95 models can suffer from the 'unobserved variables bias', because the unobserved characteristics may not be distributed independently of the explanatory variables. In order to address the unobserved heterogeneity bias, a Mundlak version of the BC95 model originally proposed by Battese and Coelli (1995) is estimated. ${ }^{10}$ The Mundlak version of the BC95 (BC95M hereafter) is based upon Mundlak's (1978) modification of the BC95 for the general specification; whereby the correlation of the individual specific effects $\left(a_{i}\right)$ and the explanatory variables are considered in an auxiliary equation given by:

$$
a_{i}=A X_{i} \pi+\gamma_{i}, \quad A X_{i}=\frac{1}{T} \sum_{t=1}^{T} X_{i t}, \quad \gamma_{i} \sim \operatorname{iid}\left(0, \sigma_{\delta}^{2}\right)
$$

where $X_{i t}$ is the vector of all explanatory variables, $A X_{i}$ is the vector of the averages of all the explanatory variables, and $\pi$ is the corresponding vector of coefficients. ${ }^{11}$ By replacing constant with $a_{i}$, Equation (4) is readily incorporated in the main frontier Equation (2) and estimated using the BC95 model. Nevertheless, in a frontier model the error term is a composite asymmetric term and consequently the estimated coefficients are not the within estimators as in Mundlak's classical formulation. However, since the correlation between the individual effects and the explanatory variables is at least partially captured in the model, the heterogeneity bias is expected to be relatively low. Moreover, the application of Mundlak's adjustment to the BC95 frontier framework should decrease the bias in inefficiency estimates by separating inefficiency from unobserved heterogeneity. ${ }^{12}$ In fact, the term $\gamma_{i}$ of the Mundlak adjustment in Equation (4) should represent the time persistent inefficiency and should be absorbed in the inefficiency term. Of course, the possibility that this term 
is absorbed by the error term cannot be excluded. In this case, the inefficiency term would include only partially the time persistent inefficiency.

Given the discussion above, the BC95M is the preferred model, but for comparison purposes the BC95 and the TFE models are also estimated. ${ }^{13}$ The TFE model is estimated by ML method by simply creating dummy variables $\left(a_{i}\right)$ for each member state. Here $a_{i}$ is a country-specific time-invariant fixed effect meant to capture crosscountry unobserved heterogeneity.

The estimated energy-efficiency level is usually expressed in terms of efficiency score:

$$
E F_{i t}=\frac{E D_{i t}}{E D_{i t}^{F}}=\exp \left(-\hat{u}_{i t}\right)
$$

where $E D_{i t}$ is the observed final energy demand and $E D_{i t}^{F}$ is the respective frontier demand of the $i$-th member state in time $t$. An efficiency score of one indicates an energy efficient member state in year $t$. Alternatively, an energy inefficiency score can be calculated as the reciprocal of efficiency score $\left(E F_{i t}\right)$ in Equation (5).

\section{Data}

The study is based on an unbalanced panel data set for a sample of $27 \mathrm{EU}$ member states $(i=1, \ldots, 27)$ over the period 1996 to $2009(t=1, \ldots, 14)$. Due to the missing data on average dwelling size one member state, namely Malta, had to be excluded 
from the analysis. $E D_{i t}$ for a given member state $i$ in year $t$ is the final residential energy consumption measured in tonnes of oil equivalent (toe). $P E_{i t}$ represents the real energy price, calculated based on the harmonised index of consumer energy prices where $2005=100$. Real income, $Y_{i t}$, is approximated by GDP in purchasing power parity and constant US\$ prices. $D S I Z E_{i t}$ denotes average dwelling size of a household, measured in square meters. To control for differences in climate conditions, the data on heating degree days $\left(H D D_{i t}\right)$ is utilised. As the data on cooling degree days is not available, a dummy variable corresponding to the hot climate $H O T_{i}$ is considered in the model. Descriptive statistics of the variables included in the model are presented in Table 2. It can be seen that the variables show considerable variation between member states in the observed period. The data is obtained from various sources which include Eurostat, IEA and Odyssee databases.

Further, the construction of the variables on energy policy instruments is based on information taken from MURE II database and presented in Table $1 .{ }^{14}$ This database includes applied national measures defined in National Energy Efficiency Action Plans and EU-related measures implemented in line with the EU directives. These measures were furthermore classified in three different groups which correspond to the most frequently used measure types, namely (i) energy performance standards, (ii) financial and fiscal incentives, and (iii) informative measures. Energy performance standards were furthermore broken into categories corresponding to standards related to buildings and heating systems, standards related to electrical appliances and other measures. Since different measures are often not comparable in terms of scope, impact and required funding, several dummy variables were created, 
which should reflect both the presence of some measures as well as the number of measures. This is arguably a relatively simplistic approach because, as already mentioned, the measures are heterogeneous; hence, counting the number of measures introduced in each group could be imprecise. However, it is believed that this approximation should capture the most important developments in the introduction of energy policy measures in each country. Moreover, given the analysis is for EU member countries, for consistency, the general structure in the definition of the energy policy measures are followed, which also supports this decision. A similar approach is adopted in Bigano et al. (2011), where the data on energy efficiency policies and measures used in this study is also obtained from MURE database. Dummy variables are created for subcategory of policies where value of one denotes that any kind of policy is implemented in a given country during the period investigated. Alternatively, in Saussay et al. (2012) the respective policy variable introduced in the model represents the number of years elapsed since building energy codes were implemented.

$B H 1_{i t}$ is equal to 1 if one or two energy performance standards related to buildings or heating systems were in place in a given member state and a given year, or 0 otherwise. Similarly, $B H 2_{i t}$ is equal to 1 if three or more such performance standards were in place. $A P P_{i t}$ denotes whether at least one measure related to performance standards of electrical appliances was introduced by a member state in a given year. Furthermore, $F I N 1_{i t}$ indicates whether a member state in a given year implemented one or two financial incentives to promote energy efficient investments (e.g., grants, subsidies, loans with reduced interest rate, tax reductions), while $F I N 2_{i t}$ indicates whether three or more financial measures were implemented. Taking two measures 
as a threshold to define two separate dummy variables in the case of both financial incentives and building and heating performance standards corresponds to the median value of the number of measures in place in a member state in a given year. $I N F O_{i t}$ denotes whether at least one informative measure was introduced such as mandatory labelling of appliances, advice network for citizens or information campaigns by specialised agencies. Likewise, in the case of informative measures two separate dummies could be considered. The decision to keep only one informative dummy in the model is based on preliminary model estimations which showed that these two dummies did not prove to be significant or have the expected signs.

Table 2: Descriptive statistics

\begin{tabular}{|c|c|c|c|c|c|}
\hline Variable & Mean & Std. Dev. & Min & Max & $\mathbf{N}$ \\
\hline $\begin{array}{l}E D \\
\text { (in thousands toe) }\end{array}$ & $11,601.6$ & $16,181.0$ & 145.0 & $72,281.0$ & 349 \\
\hline $\begin{array}{l}P E \\
(2005=100)\end{array}$ & 92.1 & 25.1 & 21.3 & 196.0 & 349 \\
\hline $\begin{array}{l}Y \\
\text { (in billion } 2005 \text { US\$ in PPP) }\end{array}$ & 494.9 & 684.4 & 12.1 & $2,777.7$ & 349 \\
\hline $\begin{array}{l}P O P \\
\text { (in million) }\end{array}$ & 18.9 & 23.0 & 0.4 & 82.5 & 349 \\
\hline $\begin{array}{l}D S I Z E \\
\left(\text { in }^{2}\right)\end{array}$ & 85.1 & 18.5 & 52.5 & 140.0 & 349 \\
\hline $\begin{array}{l}H D D \\
\text { (in degree days) }\end{array}$ & $2,995.6$ & $1,120.2$ & 581.7 & $5,994.3$ & 349 \\
\hline $\begin{array}{l}\text { HOT } \\
(1-\text { hot climate, } 0-\text { otherwise })\end{array}$ & 0.2006 & 0.4010 & 0.0 & 1.0 & 349 \\
\hline $\begin{array}{l}\text { BHI (1 - } 1 \text { or } 2 \text { EPS for buildings \& } \\
\text { heating systems; } 0 \text { - otherwise) }\end{array}$ & 0.3868 & 0.4877 & 0.0 & 1.0 & 349 \\
\hline $\begin{array}{l}\text { BH2 }(1-3 \text { or more EPS for buildings } \\
\& \text { heating systems; } 0-\text { otherwise })\end{array}$ & 0.3926 & 0.4890 & 0.0 & 1.0 & 349 \\
\hline $\begin{array}{l}A P P(1-\text { EPS for electrical appliances } \\
\text { or lightning; } 0 \text { - otherwise })\end{array}$ & 0.2579 & 0.4381 & 0.0 & 1.0 & 349 \\
\hline $\begin{array}{l}I N F O(1-\text { informative measures; } 0- \\
\text { otherwise })\end{array}$ & 0.7450 & 0.4365 & 0.0 & 1.0 & 349 \\
\hline $\begin{array}{l}\text { FIN1 (1-1 or } 2 \text { financial \& fiscal } \\
\text { measures; } 0-\text { otherwise) }\end{array}$ & 0.4012 & 0.4908 & 0.0 & 1.0 & 349 \\
\hline $\begin{array}{l}\text { FIN2 (1-3 or more financial \& fiscal } \\
\text { measures; } 0 \text { - otherwise) }\end{array}$ & 0.3238 & 0.4686 & 0.0 & 1.0 & 349 \\
\hline
\end{tabular}




\section{Results}

\subsection{Estimated energy demand model}

The estimation results of the residential energy demand model using different SFA approaches are given in Table 3. Since energy consumption and the regressors relating to the continuous variables are in logarithms the estimated coefficients are directly interpretable as demand elasticities. The estimated coefficients prove to have the expected signs and are generally statistically significant in all models. The exception can be found in the estimated price coefficient in the BC95 model, which is in contrast with theoretical expectations found to be positive but insignificant. However, by using Mundlak's correction in estimation of the BC95M model, the negative and highly significant price effect can be established. Significant coefficients related to the Mundlak's correction indicate the need to control for heterogeneity that is correlated with explanatory variables in order to avoid biased estimates. The TFE model which controls for time-invariant country-specific unobserved heterogeneity also results in negative and significant price effect on residential energy demand. The estimated own price elasticity of the BC95M and TFE models is estimated to be -0.26 and -0.19 , respectively.

The estimated income elasticity is positive and significant in all three models. The results suggest that the EU residential energy demand is price and income inelastic, which is similar to the obtained results for the US residential consumption in 
Filippini and Hunt (2012). As expected, population size also has a positive and highly significant influence on residential energy demand in all models. Moreover, the coefficient for dwelling size is found to be negative and significant in the BC95 and TFE model, while BC95M model does not result in significant coefficient estimate. Negative dwelling size effect on residential energy demand may be explained by the fact that dwelling size is positively correlated with household size. The two climate variables appear to have a consistent and significant influence on residential energy demand. Higher heating degree days are positively and significantly associated with higher residential energy demand, while in the case of the hot climate negative relationship is established. The hot climate dummy is not included in the TFE model as its influence is already captured by the time-invariant country specific effects.

Furthermore, the time trend is only shown to significantly reduce energy demand in the BC95 model, but is not found to be significant in the BC95M and TFE models. According to Filippini and Hunt (2012) a possible explanation for these established differences may be found in the fact that different models capture the impact of technological innovation and behavioural change on the energy consumption in different ways, that is either through price effects, time trend or inefficiency terms.

\subsection{Energy efficiency estimates}

The results of the econometric analysis reported in Table 3 can be used to estimate the level of energy efficiency. Significant estimates of parameter lambda obtained, which indicates the relative contribution of the variance in inefficiency term compared to 
the variance in random noise, denotes that considerable inefficiency is in fact present in the model. Descriptive statistics of the level of energy efficiency are reported in Table 4. Overall, a fair degree of variation among the EU member states is established in energy efficiency estimates, indicating that there is still considerable room for improvement. The estimated average energy efficiency resulting from the BC95 model is $83.4 \%$. By controlling for heterogeneity associated with explanatory variables in the $\mathrm{BC} 95 \mathrm{M}$ model or alternatively, by controlling for time-invariant country-specific unobserved heterogeneity in the TFE model, the estimated average energy efficiency is increased and amounts to $89.6 \%$ and $94.0 \%$ respectively.

As already noted, the BC95 model does not control for heterogeneity and may therefore estimate inefficiencies in an imprecise way. On the other hand, inefficiencies of the TFE model may be underestimated as they do not include the persistent inefficiencies that might remain constant over time and are captured by the individual effects. TFE model commonly results in very high average efficiency scores and small differences in efficiency scores between different countries, so there may be virtually nothing left to be explained by different policy measures in place. The BC95M model which uses Mundlak’s correction in order to control for unobserved heterogeneity is, therefore, viewed to be the most appropriate model for analysing the level of energy efficiency of the EU residential sector. ${ }^{15}$ 
Table 3: Estimated residential energy demand function

\begin{tabular}{|c|c|c|c|}
\hline Parameter & $\begin{array}{l}\mathrm{BC95} \\
\text { model }\end{array}$ & $\begin{array}{l}\text { BC95M } \\
\text { model }\end{array}$ & $\begin{array}{l}\text { TFE } \\
\text { model }^{\mathrm{a}}\end{array}$ \\
\hline \multicolumn{4}{|c|}{ Parameters of the demand function } \\
\hline Constant & $\begin{array}{l}5.4989 * * * \\
(0.8231)\end{array}$ & $\begin{array}{c}0.3779 \\
(0.9425)\end{array}$ & $\begin{array}{l}-8.3131 * * * \\
(3.1866)\end{array}$ \\
\hline$L P E$ & $\begin{array}{c}0.0449 \\
(0.0810)\end{array}$ & $\begin{array}{l}-0.2561 * * * \\
(0.0594)\end{array}$ & $\begin{array}{l}-0.1857 * * * \\
(0.0371)\end{array}$ \\
\hline$L Y$ & $\begin{array}{l}0.6962 * * * \\
(0.0287)\end{array}$ & $\begin{array}{l}0.3318 * * * \\
(0.1005)\end{array}$ & $\begin{array}{l}0.4199 * * * \\
(0.0568)\end{array}$ \\
\hline$\angle P O P$ & $\begin{array}{l}0.3014 * * * \\
(0.0262)\end{array}$ & $\begin{array}{l}0.7252 * * * \\
(0.1957)\end{array}$ & $\begin{array}{l}1.2598 * * * \\
(0.1608)\end{array}$ \\
\hline$L D S$ & $\begin{array}{l}-0.3193 * * * \\
(0.0739)\end{array}$ & $\begin{array}{c}0.3428 \\
(0.3056)\end{array}$ & $\begin{array}{l}-0.4327 * * \\
(0.2023)\end{array}$ \\
\hline LHDD & $\begin{array}{l}0.3348 * * * \\
(0.0372)\end{array}$ & $\begin{array}{l}0.3473 * * * \\
(0.1256)\end{array}$ & $\begin{array}{l}0.3708 * * * \\
(0.0594)\end{array}$ \\
\hline$t$ & $\begin{array}{l}-0.0146^{* * * *} \\
(0.0028)\end{array}$ & $\begin{array}{c}0.0006 \\
(0.0046)\end{array}$ & $\begin{array}{l}-0.0028 \\
(0.0024)\end{array}$ \\
\hline$H O T$ & $\begin{array}{l}-0.4225^{* * * *} \\
(0.0409)\end{array}$ & $\begin{array}{l}-0.5839 * * * \\
(0.0342)\end{array}$ & I \\
\hline$M L P E$ & I & $\begin{array}{l}1.1016 * * * \\
(0.1333)\end{array}$ & I \\
\hline$M L Y$ & I & $\begin{array}{l}0.3165 * * * \\
(0.1021)\end{array}$ & I \\
\hline$M L P O P$ & / & $\begin{array}{l}-0.3746^{* *} \\
(0.1882)\end{array}$ & / \\
\hline$M L D S$ & / & $\begin{array}{l}-0.0189 \\
(0.1337) \\
\end{array}$ & / \\
\hline$M L H D D$ & / & $\begin{array}{l}-0.4596 \\
(0.3101)\end{array}$ & / \\
\hline \multicolumn{4}{|c|}{ Parameters in the one-sided error } \\
\hline Constant & $\begin{array}{l}0.3378 * * * \\
(0.0639)\end{array}$ & $\begin{array}{l}0.3570 * * * \\
(0.1370)\end{array}$ & I \\
\hline BHI & $\begin{array}{l}-0.1636 * * \\
(0.0642) \\
\end{array}$ & $\begin{array}{l}-0.1798 * \\
(0.1025)\end{array}$ & $\begin{array}{c}0.0063 \\
(0.0980)\end{array}$ \\
\hline $\mathrm{BH} 2$ & $\begin{array}{l}-0.1315^{*} \\
(0.0687) \\
\end{array}$ & $\begin{array}{l}-0.1170 \\
(0.0936) \\
\end{array}$ & $\begin{array}{l}-0.2273 \\
(0.1710) \\
\end{array}$ \\
\hline$A P P$ & $\begin{array}{l}-0.1782 \\
(0.1093) \\
\end{array}$ & $\begin{array}{l}-0.1714^{*} \\
(0.1031) \\
\end{array}$ & $\begin{array}{c}0.1131 \\
(0.0947) \\
\end{array}$ \\
\hline INFO & $\begin{array}{l}0.1384 * * \\
(0.0568) \\
\end{array}$ & $\begin{array}{r}0.1749 * \\
(0.0964) \\
\end{array}$ & $\begin{array}{l}-0.0154 \\
(0.0874) \\
\end{array}$ \\
\hline FIN1 & $\begin{array}{l}-0.2926 * * * \\
(0.0819)\end{array}$ & $\begin{array}{l}-0.4873 * * \\
(0.2107)\end{array}$ & $\begin{array}{l}-0.3305 * * * \\
(0.1213)\end{array}$ \\
\hline FIN2 & $\begin{array}{l}-0.2170 * * * \\
(0.0633)\end{array}$ & $\begin{array}{l}-0.4698 * * * \\
(0.1042)\end{array}$ & $\begin{array}{l}-0.8559 * * * \\
(0.2827)\end{array}$ \\
\hline Variance par & e compound & & \\
\hline Sigma & $\begin{array}{l}0.1872 * * * \\
(0.0184)\end{array}$ & $\begin{array}{l}0.2369 * * * \\
(0.0282)\end{array}$ & $\begin{array}{l}0.1966 * * * \\
(0.0279)\end{array}$ \\
\hline Lambda & $\begin{array}{l}1.8263 * * * \\
(0.5482)\end{array}$ & $\begin{array}{l}9.2408 * * * \\
(3.5860)\end{array}$ & $\begin{array}{l}7.7338 * * * \\
(1.7583)\end{array}$ \\
\hline
\end{tabular}

Notes: ${ }^{\text {a }}$ - country specific dummies (ranging from -0.31 to 3.37 ) are not reported in the table. $* * *, * *, *$ - significant at $1 \%, 5 \%$ and $10 \%$ level, respectively. 
Table 4: Estimated energy efficiency scores

\begin{tabular}{lcrllr}
\hline Variable & Mean & Std. Dev. & Min & Max & \multicolumn{1}{c}{ Cases } \\
\hline EFBC95 & 0.8340 & 0.0989 & 0.6230 & 0.9708 & 349 \\
\hline EFBCM95 & 0.8961 & 0.0453 & 0.8590 & 0.9882 & 349 \\
\hline EFTFE & 0.9398 & 0.0437 & 0.8607 & 0.9926 & 349 \\
\hline
\end{tabular}

Energy efficiency scores are expected to be negatively correlated with energy intensity, since a level of energy intensity is supposed to decrease with an increase in energy efficiency. Nevertheless, the efficiency estimates from BC95M are found to be very poorly correlated with energy intensity $(E I)$, which is approximated by the average residential energy demand and with the average consumption per dwelling. ${ }^{16}$ This arguably supports the view that energy intensity can only be viewed as a rough proxy for energy efficiency. While for some countries energy intensity indicator may be viewed as a good proxy of energy efficiency, this does not hold in general.

Using the average values of the estimated energy efficiency scores for each EU member state obtained with the BC95M, three groups of countries are identified, namely relatively efficient states (state specific average value of the level of efficiency higher than the third quartile), relatively inefficient states (state specific average value of the level of efficiency lower than the median efficiency level) and relatively speaking moderately efficient states (state specific average value of the level of efficiency between the median and the third quartile). From the results reported in Table 5 it is interesting to observe that there is no clear division between 
old and new EU member states, since in both groups good and bad practice countries can be identified.

Table 5: Classification of member states based on the estimated average energy efficiency

\begin{tabular}{lll}
\hline $\begin{array}{l}\text { Energy efficiency } \\
\text { score }(\boldsymbol{E} \boldsymbol{F B C M})\end{array}$ & Group & Member states \\
\hline Below $86 \%$ & Inefficient states & BE, CY, DE, DK, EE, FI, GR, HU, IT, LV, PT \\
\hline From 86\% to 93\% & Moderately efficient states & AT, FR, LU, PL, RO, SE, SI, SK \\
\hline Above 93\% & Efficient states & BG, CZ, ES, IE, LT, NL, UK \\
\hline
\end{tabular}

5.3 Impact of energy efficiency measures on estimated energy efficiency levels

The results on the impact of the energy policy instruments adopted in the EU member states show that several instruments influence the level of energy efficiency of the residential sector. In particular financial incentives seem to have an important influence on reducing energy inefficiency of the residential sector in the EU member states. Both financial dummies introduced in the model to capture the effect of adopted financial measures, namely FIN1 and FIN2, prove to be negative and highly significant in all models.

There is also some evidence that performance standards of buildings, heating systems and appliances contribute to improved efficiency, while informative measures $(I N F O)$ do not seem to have an influence on the inefficiency level (TFE model) or are even found to increase the level of inefficiency in the other two models. This is, of course, a counterintuitive result and due to the wrong sign 
obtained it is not found significant under the two-sided hypothesis in the BC95M model. Since informative measures, among others, also consist of labelling, a possible explanation of the obtained sign could be found in the rebound effect, where people buy energy-saving appliances, but at the same time change behaviour in the direction of increased consumption of energy services (Sorrell, 2009).

The relationship between inefficiency and one or two introduced performance standards of buildings and heating systems $(B H 1)$ is found to be significant and negative in both BC95 and BC95M model. Furthermore, three or more introduced performance standards of buildings and heating systems $(\mathrm{BH} 2)$ prove to be significant in the BC95 model, while performance standards of electrical appliances $(A P P)$ prove to be significant in the BC95M model. To perform a robustness check, the three models were re-estimated with the number of energy efficiency measures replacing the respective dummies. Similar results are obtained, although somewhat lower significance levels are found. In addition, to test whether several types of measures have a larger impact compared to only one type of measures in place, interactions between energy efficiency dummies were also considered. However, none of the interaction terms proved to be significant.

The relatively low impact of standards on the level of energy efficiency of buildings and heating systems may be due to the fact that these standards have generally an impact on energy efficiency in the longer term as they mostly refer to new buildings. This result could be due to the fact that the construction rate of new buildings and the renovation rate of old buildings are relatively small and the standards apply generally to new buildings. In summary, in can be concluded that the established results 
provide some evidence on the effectiveness of the EU policy measures related to promotion of energy-efficiency in the observed period.

\section{Conclusions}

Following the approach proposed by Filippini and Hunt $(2011,2012)$ this paper employs a frontier demand energy model to estimate the 'underlying energy efficiency' of residential sector for each EU member state over the period 1996 to 2009. Compared to the widely used energy intensity indicator this is argued to be a more appropriate measure of energy efficiency since it is able to control for differences in socio-economic and environmental factors among the member states. In addition, the study also considers two alternative approaches to control for unobserved heterogeneity and separate it from inefficiency estimates. The results suggest that the rankings of member states based on energy intensity and energy efficiency levels may substantially differ. Therefore, energy intensity indicator cannot be considered as a good proxy for energy efficiency and should be combined with other indicators in order to derive relevant policy conclusions.

The estimated average energy efficiency level based on the preferred Battese and Coelli (1995) model with Mundlak correction (1978) implies that there is a significant potential for a decrease in energy consumption of households. Considerable variation in energy efficiency between the EU member states is established, implying that countries have not been equally successful in promoting energy savings. In terms of energy efficiency performance no clear distinction between old and new EU member states can be established. Additionally, in the 
period under investigation no notable technical change is found in the EU residential sector. As noted by Kumbhakar and Lovell (2000, p. 107), this may also reflect the fact that sometimes it is difficult to disentangle the effect of movement to the frontier and frontier shift.

In attempt to provide some evidence on the effectiveness of energy efficiency measures implemented in the EU residential sector, several relevant policy measures are considered in the model. The results imply that improved energy efficiency can be linked to the introduced financial incentives and energy performance standards, while informative measures such as labelling and educational campaigns do not show to have significant effect in fostering energy efficiency improvements. The results are also found to be in line with results from previous studies. In Saussay et al. (2012) building energy codes are established to have a significant effect on the improvement of residential space heating energy efficiency in the selected EU countries. Bigano et al. (2011) also find the positive impact of the EU energy efficiency policies on energy intensity and what seems to work is policy mix rather than a single policy in isolation. Therefore, findings from our analysis provide useful policy implications for further enhancing energy efficiency in the EU.

\section{References}

ADEME, 2009. Energy Efficiency Trends and Policies in the EU 27, Results of the ODYSSEEMURE project. Paris, October 2009.

Aigner, D. J., Lovell, C. A. K., Schmidt, P., 1977. Formulation and Estimation of Stochastic Frontier Production Function Models. Journal of Econometrics, 6(1), 21-37. 
Ang, B.W., 2006. Monitoring changes in economy-wide energy efficiency: From energy - GDP ratio to composite efficiency index. Energy Policy, 32(9), 1131-1139.

Banfi, S., Filippini, M., Hunt, L., 2005. Fuel tourism in border regions: The case of Switzerland. Energy Economics, 27, 689-818.

Battese, G.E., Coelli, T.J., 1995. A Model for Technical Inefficiency Effects in a Stochastic Frontier Production Function for Panel Data. Empirical Economics, 20, 325-332.

Bigano, A., Arigoni Ortiz, R., Markandya, A., Menichetti, E., Pierfederici, R., 2011. The linkages between energy efficiency and security of energy supply in Europe, in Galarraga, I., GonzálezEguino, M., Markandya, A. (Eds.), Handbook of sustainable energy. Edward Elgar Publishing Ltd., Northampton, pp. 60-83.

Council of the EU, 1998. Council Resolution of 7 December 1998 on energy efficiency in the European Community. OJ C 391/1.

Deaton, A. and Muellbauer, J., 1980. Economics and Consumer behaviour. Cambridge University Press, Cambridge.

Directive 2006/32/EC of the European Parliament and of the Council of 5 April 2006 on energy enduse efficiency and energy services and repealing Council Directive 93/76/EEC. OJ L 114, 27 April 2006.

Directive 2012/27/EU on energy efficiency, amending Directives 2009/125/EC and 2010/30/EU and repealing Directives 2004/8/EC and 2006/32/EC. OJ L315, 14 November 2012.

European Commission (EC), 1998. Communication from the Commission. Energy Efficiency in the European Community - Towards a Strategy for the Rational use of Energy. COM(1998) 246 final. Brussels, 29.04.1998.

EC, 2000. Communication from the Commission to the Council, the European Parliament, the Economic and Social Committee and the Committee of the Regions. Action Plan to Improve Energy Efficiency in the European Community. COM(2000) 247 final. Brussels, 26.04.2000.

EC, 2005. Green Paper on Energy Efficiency or Doing More with Less. COM(2005) 265 final. Brussels, 22.06.2005. 
EC, 2006. Communication from the Commission. Action Plan for Energy Efficiency: Realising the Potential. COM(2006) 545 final. Brussels, 19.10.2006.

EC, 2010. Communication from the Commission to the European Parliament, the Council, the European Economic and Social Committee and the Committee of the Regions. Energy 2020 - a strategy for competitive, sustainable and secure energy. COM (2010) 639 final, Brussels, 10 November 2010.

EC, 2011a. Impact Assessment. Commission Staff Working Paper, SEC(2011) 780 final. Brussels, 22.6.2011.

EC, 2011b. Communication from the Commission to the European Parliament, the Council, the European Economic and Social Committee and the Committee of the Regions. Energy Efficiency Plan 2011. COM(2011) 109 final. Brussels, 8.3.2011.

European Environment Agency, 2011. Energy efficiency and energy consumption in the household sector (ENER 022) - Assessment published Aug 2011. Available at: http://www.eea.europa.eu/dataand-maps/indicators/energy-efficiency-and-energy-consumption-2/assessment-2.

Eurostat. http://epp.eurostat.ec.europa.eu/portal/page/portal/statistics/search_database. Accessed on 10 June 2012.

Evans, J., Filippini, M., Hunt, L.C., 2013. The contribution of energy efficiency towards meeting CO2 targets, Chapter 8 in Fouquet, R. (Ed.): Handbook of Energy and Climate Change. Edward Elgar, Cheltenham, forthcoming.

Farsi, M., Filippini, M., 2009. An Analysis of Cost-Efficiency in Swiss Multi-utilities. Energy Economics, 31, 306-315.

Filippini, M., Pachauri S., 2004. Elasticities of electricity demand in urban Indian households. Energy Policy, 32, 429-436.

Filippini, M., Hunt, L. C., 2011. Energy demand and energy efficiency in the OECD countries: a stochastic demand frontier approach. The Energy Journal, 32(2), 59-80.

Filippini, M., Hunt, L.C., 2012. US Residential Energy Demand and Energy Efficiency: A Stochastic Demand Frontier Approach. Energy Economics, 34(5), 1484-1491. 
Greene, W., 2005a. Reconsidering Heterogeneity in Panel Data Estimators of the Stochastic Frontier Model. Journal of Econometrics, 126, 269-303.

Greene, W., 2005b. Fixed and random effects in stochastic frontier models. Journal of Productivity Analysis, 23, 7-32.

IEA, 2007. Energy Use in the New Millenium - Trends in IEA countries. OECD/IEA, Paris.

IEA, 2009. Progress with implementing energy efficiency policies in the G8. OECD/IEA, Paris.

IEA, 2012. Energy Balances of OECD Countries (Edition: 2012). ESDS International, University of Manchester, DOI: http://dx.doi.org/10.5257/iea/ebo/2012.

Kopp, R.J., 1981. The Measurement of Productive Efficiency: A Reconsideration, Quarterly Journal of Economics, 97, 477-503.

Kumbhakar, S.C., Lovell, C.A.K., 2000. Stochastic Frontier Analysis. Cambridge University Press, Cambridge.

Kumbhakar, S.C., Ghost, S., McGuckin, J.T., 1991. A Generalized Production Frontier Approach for Estimating Determinants of Inefficiency in US Dairy Farms. Journal of Business and Economic Statistics, 9(3), 279-286.

Mundlak, Y., 1978. On the Pooling of Time Series and Cross-Section Data. Econometrica, 46(1), 6985.

MURE II. Database on energy efficiency policies and measures. http://www.muredatabase.org/. Accessed on 19 June 2012.

Odyssee, 2011. Database on the energy consumption drivers by end-use, energy efficiency and $\mathrm{CO}_{2}$ related indicators. http://www.odyssee-indicators.org/database/database.php (subscription-based).

Pitt, M., Lee, L.F., 1981. The Measurement and Sources of Technical Inefficiency in the Indonesian Weaving Industry. Journal of Development Economics, 9, 43-64.

Reinhard S, Lovell C. A. K., Thijssen G. J., 1999. Econometric estimation of technical and environmental efficiency: An application to Dutch dairy farms. American Journal of Agricultural Economics, 81, 44-60. 
Saussay, A., Saheb, Y., Quirion P., 2012. The Impact of Building Energy Codes on the Energy Efficiency of Residential Space Heating in European countries - A Stochastic Frontier Approach. International Energy Program Evaluation Conference, 12-14 June 2012, Rome.

Schmidt, P., Lovell, C.A.K., 1979. Estimating Technical and Allocative Inefficiency Relative to Stochastic Production and Cost Frontiers. Journal of Econometrics, 9, 343-366.

Sorrell, S., 2009. The rebound effect: definition and estimation, Chapter 9 in Hunt, L., and Evans, J. (Eds.): International Handbook of the Economics of Energy, Edward Elgar, Cheltenham, 199-233. Zhou, P., Ang, B.W., 2008. Linear programming models for measuring economy-wide energy efficiency performance. Energy Policy, 36, 2911-2916.

\section{Footnotes}

\footnotetext{
${ }^{1}$ See Kumbhakar and Lovell (2000) for a discussion on the microeconomic theory of production and on the definition of productive efficiency.

${ }^{2}$ Another approach to overcome the problem related to the use of simple energy intensity indicators can be found in Index Decomposition Analysis (IDA), which is in principle a bottom-up framework. For details on this method, see Ang (2006). Alternatively, a non-parametric frontier method DEA is used in Zhou and Ang (2008) to measure energy efficiency performance of selected OECD countries. ${ }^{3}$ Official EU documents typically view energy efficiency improvements as decreased energy intensity or reduced energy consumption. Since this paper advocates the use of alternative measure of energy efficiency and in order to use consistent terminology throughout the paper, in this section the use of the term 'energy efficiency improvements' is explicitly avoided and instead expressions such as energy savings, reduced energy consumption or decreased energy intensity are utilised.

${ }^{4}$ See Filippini and Pachauri (2004) and Banfi et al. (2005) for an application of household production theory to energy demand analysis.

${ }^{5}$ Note, that by estimating a production or distance frontier function it is possible using the empirical approach suggested by Reinhard et al.(1999) to estimate an input specific technical efficiency indicator. For instance, Reinhard et al. (1999) estimate the level of water efficiency for a sample of
} 

econometrically the economic performance of production processes at the firm level. It was introduced by Aigner et al. (1977) and since then many modifications of the original method have been proposed. See, for example, Kumbhakar and Lovell (2000).

${ }^{7}$ An alternative way to capture the impact of the UEDT on energy consumption is to use time dummies as suggested by Filippini and Hunt (2012). This approach is not employed in this study since preliminary analysis resulted in insignificant time dummy coefficients.

${ }^{8}$ For a general discussion on the use of SFMs in the energy sector, see Farsi and Filippini (2009). ${ }^{9}$ Battese and Coelli (1995) extended the approach by Kumbhakar, Ghost and McGuckin (1991) to accommodate panel data. However, it should be noted that this model does not in fact exploit the panel aspect of the data set in order to deal with the unobserved heterogeneity.

${ }^{10}$ Note, Filippini and Hunt (2012) utilize the Mundlak's modification to the Pitt and Lee (1981) model instead. Limitation of the latter model is the assumption on time invariant inefficiency that cannot account for the impact of introduced policy measures.

${ }^{11}$ Note that the Mundlak's formulation (i.e. with the introduction of this auxiliary equation in a random effects model) produces the 'Within Estimator'. In its original form, the Mundlak (1978) general panel data regression model is $Q_{i t}=X_{i t} \beta+A X_{i} \pi+\gamma_{i}+v_{i t}$; however, Mundlak (1978) showed that the estimation of this model using GLS yields: $\hat{\beta}_{G L S}=\hat{\beta}_{\text {within }}$ and $\hat{\pi}_{G L S}=\hat{\beta}_{\text {Between }}-\hat{\beta}_{\text {within }}$. The direct interpretation of the coefficients $\hat{\pi}_{G L S}$ is therefore not straightforward. Usually, the discussion on the results concentrates on $\hat{\beta}_{\text {within }}$.

${ }^{12}$ In this specification, it is assumed that the effects of unobserved country characteristics are captured by the coefficients of the group mean of the explanatory variables of Equation (4).

${ }^{13}$ Note, in Filippini and Hunt (2011) and Filippini and Hunt (2012) the focus was not on the impact of policy measures on efficiency and for this reason the pooled model by Aignar et al. (1977) and the random-effects model by Pitt and Lee (1981) are used as preferred models, respectively. In the latter case Mundlak's correction (1978) is introduced, while no such correction proved to be necessary in the former case. By ignoring the augmentation of the model provided in Equation (3), Battese and 

of the data.

${ }^{14}$ MURE (Mesures d'Utilisation Rationnelle de l'Energie) is a part of the ODYSSEE MURE project on Monitoring of Energy Demand Trends and Energy efficiency in the EU, supported under the Intelligent Energy Europe Programme of the European Commission.

${ }^{15}$ The correlation coefficients between the results obtained with all three models were calculated. These results show a relatively high correlation between the results obtained with BC95 and BC95M and a moderate correlation between the TFE model on one side and the BC95 and BC95M models on the other.

${ }^{16}$ To note that the European Environment Agency is using the average consumption per dwelling as one of the simple indicators representing the level of energy efficiency of the residential sector. See http://www.eea.europa.eu/data-and-maps/indicators/energy-efficiency-and-energy-consumption2/assessment-2. 